\title{
Avaliação isocinética do membro inferior de atleta com amputação transtibial: estudo de caso
}

\author{
Isokinetic assessment of lower limb in an athlete with below-knee amputation: \\ a case study
}

\author{
Bruno Seara Polidoro', Soraia Cristina Tonon da Luz², Mário César de Andrade, Kadine Priscila Bender dos Santos ${ }^{4}$ \\ ${ }^{1}$ Fisioterapeuta graduado pela Universidade do Estado de Santa Catarina (UDESC). Florianópolis, SC. \\ ${ }^{2}$ Doutora em Alto Rendimento Esportivo, Universidade Pablo de Olavide, Sevilha. Professora do Curso de graduação e Mestrado em Fisioterapia CEFID/UDESC. \\ Florianópolis, SC. \\ ${ }^{3}$ Mestre em Ciências do Movimento Humano. Professor do Curso de graduação em Educação Física CEFID/UDESC. Florianópolis, SC. \\ ${ }^{4}$ Mestre em Educação, Universidade do Vale do Itajaí (UNIVALI). Fisioterapeuta Mestranda em Fisioterapia CEFID/UDESC. Florianópolis, SC.
}

\section{RESUMO}

Objetivos: Avaliar os efeitos de um treinamento isocinético no pico de torque e na potência máxima dos músculos flexores e extensores de joelho e quadril em um atleta amputado de membro inferior.

Descrição do Caso: Avaliou-se um atleta de Triathlon com 27 anos de idade com amputação congênita do terço proximal da tíbia à direita, usuário de prótese de alta performance para corrida. Realizou-se perimetria de ambos os membros inferiores, mensuração do pico de torque e mensuração da potência máxima da musculatura flexora e extensora de joelho e quadril, por meio de um dinamômetro isocinético antes e após duas semanas de treinamento com exercícios no isocinético. Comparando-se os dados da avaliação com os da reavaliação, através de análise descritiva exploratória, observou-se que houve redução do coeficiente de variação das quatro repetições dos movimentos de flexão e extensão de quadril e joelho de ambas as extremidades inferiores, identificando maior uniformidade nas curvas de torque na reavaliação quando comparada à avaliação inicial.

Conclusões: É fundamental um período de adaptação no dinamômetro isocinético em atletas com amputação de membro inferior, para familiarização na execução dos movimentos concêntricos e excêntricos. A ausência ou ineficiência dessa adaptação poderá comprometer os dados para a composição de protocolos de tratamento e/ou treinamento do atleta com amputação.

DESCRITORES: AMPUTAÇÃO; EXTREMIDADE INFERIOR; TERAPIA POR EXERCÍCIO.

\section{ABSTRACT}

Aims: To evaluate the effects of isokinetic training on peak torque and maximum power of the flexor and extensor muscles of the knee and hip articulations in an athlete with lower limb amputation

Case Description: We assessed a 27-year-old triathlete amputee, with congenital amputation of proximal third of right tibia and user of high-performance prosthetics for running. The circumference of both lower limbs were measured, and an isokinetic dynamometer was used to estimate the peak torque and maximum power of the flexor and extensor muscle groups of the knee and hip, before and after two weeks of training with isokinetic exercises. There was a reduction in the coefficient of variation of all four repetitions of flexion and extension of hip and knee on both lower extremities, identifying a greater uniformity in torque curves on revaluation compared to the initial evaluation.

Conclusions: Athletes with lower limb amputation should have an adjustment period with the isokinetic dynamometer in order to familiarize with the execution of concentric and eccentric movements. The absence or inefficiency of this adaptation can compromise data collection for the composition of protocols of treatment and / or training in amputee athletes.

KEY WORDS: AMPUTATION; LOWER EXTREMITY; EXERCISE THERAPY. 


\section{INTRODUÇÃO}

Atletas com deficiência têm demonstrado resultados cada vez mais impressionantes, atraindo a atenção de pesquisadores para a área do esporte. Mais do que terapia, o esporte adaptado caminha para o alto rendimento. A determinação desses atletas para alcançar um nível de atividade física satisfatório e obter sucesso no processo de reabilitação aliado ao esporte tem sido observada através da adesão ao esporte adaptado, assim como pelos resultados atingidos nas paraolímpidas. Portanto, para a obtenção do êxito competitivo, encontrar o melhor método de avaliação de cada atleta está se tornando fundamental. ${ }^{1,2}$

$\mathrm{O}$ exercício isocinético constitui-se na força muscular exercida sempre na mesma velocidade angular pré-estabelecida. ${ }^{2}$ Dispositivos isocinéticos são instrumentos para mensurar a força muscular, e sua eficácia está associada à sua característica única de fornecer máxima resistência em todos os pontos da amplitude de um movimento. Outra vantagem é o fato do paciente nunca encontrar mais resistência do que ele possa suportar - uma vez que a resistência imposta pelo aparelho é igual à força aplicada pelo indivíduo. ${ }^{3}$ O desenvolvimento da curva de torque isocinético ocorre através da mensuração de força relacionada à amplitude de movimento. Conforme apareça algum desconforto ou dor, a força aplicada pelo indivíduo diminui e o dispositivo capta essa informação como uma diminuição gráfica no torque isocinético. ${ }^{4,5}$

A dinamometria isocinética é um método de avaliação aplicável ao paciente amputado transtibial pré e pós-protetização, mostrando-se eficaz e confiável para mensurar as alterações das forças musculares. Mas vários estudos alertam para a correta execução da avaliação isocinética, assim como para a necessidade de critérios que respeitem o período de adaptação, como requisitos para a fidedignidade dos dados..$^{2,5-8}$

Indivíduos amputados de membros inferiores apresentam, entre outras complicações, atrofia muscular e diminuição de força, podendo ser encontrado um déficit de até $35 \%$ no membro amputado quando comparado ao membro contralateral. ${ }^{5}$ Os grupos musculares que mais necessitam de fortalecimento devido à amputação de membro inferior são os extensores de joelho e extensores de quadril. No entanto, deve-se considerar a modalidade esportiva praticada pelo indivíduo. ${ }^{9} \mathrm{Na}$ corrida, por exemplo, além da importância de serem bem avaliados os extensores, torna-se necessário o conhecimento da ação das musculaturas flexoras de quadril e de joelho, uma vez que estas exercem ação fundamental durante $o$ ato de correr. ${ }^{7}$
Com base nestes conhecimentos, entende-se que a avaliação de sujeitos com amputação requer um cuidado especial quanto à adaptação do membro amputado para a realização do teste, considerando os poucos estudos que abordaram a avaliação isocinética em pessoas amputadas. Dessa forma, o presente estudo teve como objetivo avaliar os efeitos de um treinamento isocinético no pico de torque e na potência máxima dos músculos flexores e extensores de joelho e quadril.

\section{RELATO DE CASO}

O estudo foi aprovado pelo Comitê de Ética em Pesquisa em Seres Humanos da Universidade do Estado de Santa Catarina (UDESC) sob parecer número 161/2008. Na avaliação inicial o sujeito assinou o termo de consentimento livre e esclarecido, que continha a descrição de todos os procedimentos a serem realizados para o estudo.

Participou do estudo um adulto do sexo masculino, atleta da seleção paraolímpica brasileira de natação, com 27 anos, altura $1,79 \mathrm{~m}$ e peso $68 \mathrm{~kg}$, com amputação congênita do terço proximal da tíbia à direita (coto de $13 \mathrm{~cm}$ ), sem evidências de contratura em flexão de joelho e com amplitude de movimento ativa e passiva preservadas em ambos os membros inferiores. Usuário de próteses com pés convencionais desde a infância e nadador há sete anos, iniciou a prática de Triathlon há dois anos, após ter adquirido prótese específica para corrida: pé de resposta dinâmica Flex Foot $^{\mathbb{R}}$ (Ossur, Califórnia, EUA).

$\mathrm{Na}$ avaliação cinésio-funcional inicial, o indivíduo não destacou queixas, entretanto referia fraqueza no membro amputado. Nessa avaliação aferiu-se peso, estatura e perimetria e marcaram-se os dias de treinamento adaptativo durante o período de duas semanas.

Nas duas semanas seguintes, foram realizados seis dias de exercícios para adaptação ao aparelho, com velocidade mantida de $60^{\circ} /$ segundo $(1,047 \mathrm{rad} / \mathrm{s})$, em três séries com 10 repetições para cada movimento. Ao término da adaptação, foi agendada a reavaliação, que foi realizada da mesma forma que a avaliação inicial, sendo analisadas as seguintes variáveis: pico de torque (PT), caracterizado pelo máximo valor encontrado nas repetições de cada avaliação; e potência máxima $\left(\mathrm{P}_{\max }\right)$ : calculada pela fórmula $\mathrm{P}_{\max }=\mathrm{PT}(\mathrm{Nm}) \times$ velocidade ( $\mathrm{rad} /$ segundo). ${ }^{7}$ Para caracterização das variáveis, utilizou-se estatística descritiva com cálculo de média, desvio padrão e coeficiente de variação da variável pico de torque. 
A perimetria foi realizada utilizando como ponto inicial de mensuração a linha articular do joelho (ponto $0 \mathrm{~cm}$ ). A partir dessa marcação foram mensurados a $5,10,15,20,25 \mathrm{~cm}$ no sentido proximal (ponto $+5,+10,+15,+20,+25)$ e no sentido distal a 5 e $10 \mathrm{~cm}$ (ponto -5 e -10 ).

Para aquisição dos dados utilizou-se um dinamômetro isocinético Kin-Com ${ }^{\circledR}$ (Chattanooga Group Inc., TN, Guarulhos, SP) composto por uma base de sustentação dos acessórios, unidade central de processamento dos dados (CPU), unidade do dinamômetro, cadeira e monitor. Os dados foram mensurados pela unidade do dinamômetro que contém uma célula de carga com sensibilidade de 1 newton e amplitude de mensuração de 1 a 2000 newtons. Para controle de velocidade e medidas de ângulos, a unidade do dinamômetro possui um tacômetro interno e um potenciômetro.

Para cada posição diferente de coleta, o equipamento permitiu ajustar a cadeira, a unidade do dinamômetro e seu braço de alavanca conforme o necessário, sempre evitando possíveis compensações do avaliado. ${ }^{3}$ Adotouse o procedimento de aquecimento global com corrida em pista atlética sintética sempre antes da avaliação com o dinamômetro isocinético. ${ }^{7,10}$ A sequência de procedimentos da avaliação inicial foi: a) aquecimento por oito minutos; b) posicionamento do sujeito na cadeira do dinamômetro já ajustada para as aquisições referentes aos joelhos, fixado por meio de tiras passando no tórax, na pelve e na coxa do segmento testado, a fim de aumentar a estabilidade e evitar compensações indesejadas. ${ }^{3}$ Para as aquisições referentes ao quadril foi adotada a posição em pé; ${ }^{11}$ c) esclarecimento ao sujeito quanto ao movimento a ser realizado com o equipamento isocinético, por meio de execuções submáximas completas sem registro dos dados. ${ }^{5-8}$

Tanto na avaliação inicial como na reavaliação foram realizadas quatro repetições para cada mensuração, com velocidade de $60^{\circ}$ /segundo ( $1,047 \mathrm{rad} /$ segundo $)$ e correção gravitacional. ${ }^{12}$ Foram avaliados movimentos de flexão e extensão das articulações do joelho e do quadril, no modo concêntrico/concêntrico seguido pelo modo excêntrico/excêntrico, nesta ordem, para cada articulação e em cada um dos membros. O sujeito foi instruído a exercer o máximo de força possível, tanto na extensão como na flexão do joelho e quadril, contando com feedback visual e encorajamento verbal. Entre as repetições o sujeito repousou por 30 segundos; entre as trocas de modo de contração 90 segundos; e entre as trocas de posicionamento,três minutos.

$\mathrm{Na}$ Tabela 1 percebem-se diferenças quanto à circunferência do membro amputado quando comparada ao membro não amputado. Como previsto, não foi observada alteração na circunferência entre a avaliação inicial e reavaliação.

Tabela 1. Perimetria de Membro Amputado e Membro não Amputado

\begin{tabular}{|c|c|c|c|c|c|}
\hline \multirow[b]{2}{*}{ Seguimento } & \multirow{2}{*}{$\begin{array}{l}\text { Diferença } \\
(\mathbf{c m})\end{array}$} & \multicolumn{2}{|c|}{ Avaliação inicial } & \multicolumn{2}{|c|}{ Reavaliação } \\
\hline & & $\begin{array}{l}\mathrm{MA} \\
(\mathrm{cm})\end{array}$ & $\begin{array}{l}\text { MNA } \\
(\mathrm{cm})\end{array}$ & $\begin{array}{l}\text { MA } \\
(\mathrm{cm})\end{array}$ & $\begin{array}{l}\text { MNA } \\
(\mathrm{cm})\end{array}$ \\
\hline \multirow[t]{5}{*}{ Coxa } & +25 & 46.5 & 53.9 & 46.5 & 54.1 \\
\hline & +20 & 43.1 & 50.4 & 43.2 & 51.2 \\
\hline & +15 & 38.6 & 45.9 & 37.6 & 46.5 \\
\hline & +10 & 33.2 & 41.4 & 32.6 & 41.9 \\
\hline & +5 & 30.1 & 37.4 & 31.8 & 36.38 \\
\hline Linha articular & 0 & 31.4 & 33.6 & 29.6 & 34.5 \\
\hline \multirow[t]{2}{*}{ Perna } & -5 & 23.1 & 31.7 & 22.8 & 33.3 \\
\hline & -10 & 17.6 & 34.1 & 16.9 & 34.8 \\
\hline
\end{tabular}

MA: membro amputado; MNA: membro não amputado.

Em relação à análise de $\mathrm{PT}$ (Figura 1) e $\mathrm{P}_{\mathrm{Max}}$ (Figura 2), houve discreto acréscimo dos parâmetros relacionados ao membro amputado antes e após as duas semanas de adaptação ao isocinético.

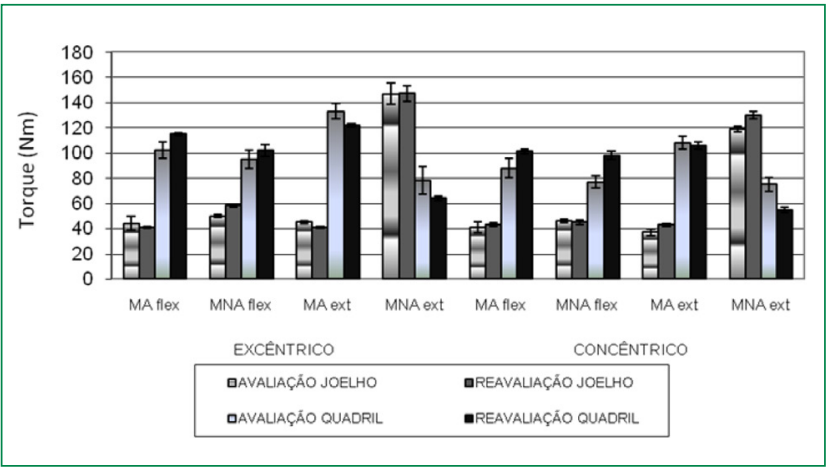

Figura 1. Pico de torque da avaliação e reavaliação de flexão/ extensão do joelho e do quadril, nos modos excêntrico e concêntrico do membro amputado (MA) e membro não amputado (MNA)

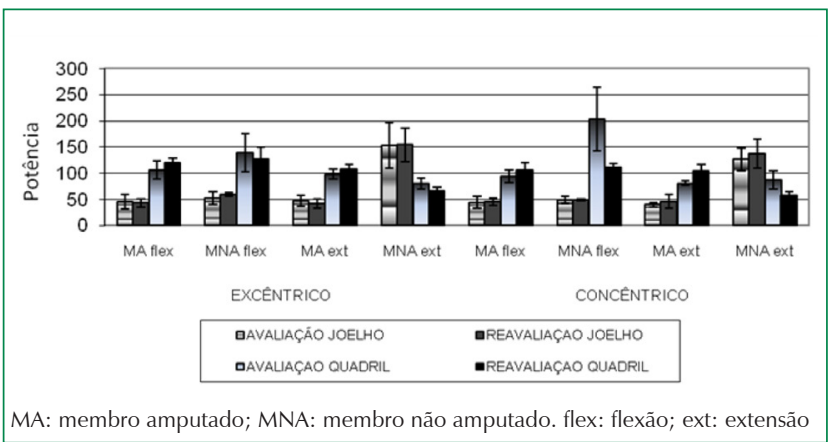

Figura 2. Potência máxima da avaliação e reavaliação de flexão/extensão do joelho e do quadril, nos modos excêntrico e concêntrico do membro amputado e membro não amputado 


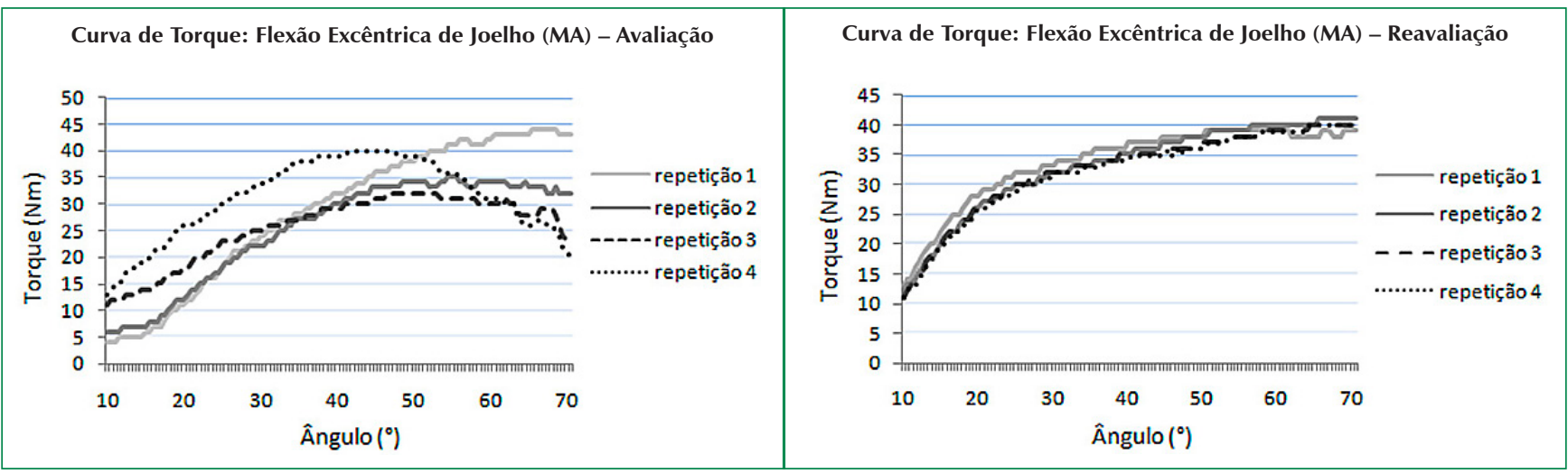

Figura 3. Demonstração da uniformidade nas repetições das curvas de torque na avaliação da flexão excêntrica de joelho do membro amputado (MA) quando comparada à reavaliação

Os resultados mais expressivos foram referentes à redução do coeficiente de variação das quatro repetições, demonstrando maior uniformidade nas curvas de torque para todos os movimentos da reavaliação quando comparada à avaliação inicial (Figura 3).

Os valores do coeficiente de variação na avaliação foram de $10,0 \%$ para a articulação do joelho e 10,8\% para o quadril. Na reavaliação, foi possível observar uma redução desses valores para 3,8\% para o joelho e $3,6 \%$ para o quadril.

\section{DISCUSSÃO}

Notou-se que com duas semanas de adaptação ao dinamômetro isocinético foi perceptível a tendência a uma maior semelhança nas curvas de PT e $\mathrm{P}_{\mathrm{Max}}$. Dessa forma, entende-se que em pacientes com amputação, a adaptação e/ou treinamento dos movimentos no aparelho mereça uma especial atenção.

Mesmo com o discreto aumento dos parâmetros de torque e potência avaliados, como previsto, não foi observado o acréscimo dos valores de perímetro de membros inferiores. Portanto, não se pode dizer que o aumento do PT ou da $\mathrm{P}_{\max }$ deveu-se a algum vestígio de hipertrofia da musculatura, mas sugere-se que tenha sido em decorrência do aprendizado que buscou atingir maior controle do movimento.

Os resultados encontrados no presente estudo são condizentes com pesquisas relativas a treinamento motor, onde o desenvolvimento da habilidade de um movimento específico induz à reorganização do circuito neural no córtex motor, o que suporta a produção de um movimento com aptidão. ${ }^{13,14}$ Sendo assim, o treino de tarefas de habilidades específicas produz sinaptogênese, potencialização sináptica e reorganização do movimento no córtex motor. Esse tipo de exercício contribui para mudanças nos reflexos espinhais que são dependentes da demanda especifica de cada tarefa. ${ }^{13,14}$

$\mathrm{O}$ aumento dos valores de PT e $\mathrm{P}_{\mathrm{Max}}$ pode consistir em adaptações neurais, tais como somação de placas motoras, aumento da ativação de músculos sinergistas ou redução de ativação dos músculos antagonistas, possibilitando a transmissão de forças de sarcômeros, individualmente, a todo o aparato músculoesquelético após os dias de adaptação ao equipamento. ${ }^{15,16}$

$\mathrm{O}$ aspecto principal encontrado na reavaliação esteve relacionado à diminuição do coeficiente de variação dos valores de PT das quatro repetições realizadas. Este dado sugere que o método utilizado para adaptação do indivíduo ao aparelho refletiu na melhora da uniformidade nas variáveis analisadas. Observou-se que a familiarização ao equipamento durante duas semanas de treinamento adaptativo pode estar relacionada à obtenção dessa uniformidade. Assim, o indivíduo pode se adequar ao dinamômetro e realizar os movimentos de forma controlada, com segurança e confiança, a fim de melhorar a reprodutibilidade do teste.

Atualmente, não há protocolos prontos que abordem a adaptação ao equipamento e, em se tratando de sujeitos com amputação, este quesito necessita de especial atenção. Existem estudos que realizam apenas uma familiarização do indivíduo com o instrumento. Por exemplo, indivíduos com e sem osteoartrose realizaram vários ciclos de flexão e extensão de joelho antes da aquisição propriamente dita. ${ }^{17}$ Outro estudo realizou, antes do teste, um exercício sub-máximo no dinamômetro, com o objetivo de aquecimento específico e também familiarização com os procedimentos de execução. ${ }^{18}$ 
A repetibilidade de medidas isocinéticas da musculatura adutora e abdutora de quadril de sujeitos jovens saudáveis foi avaliada submetendo-os a três avaliações em diferentes dias; o estudo mostrou que esses valores são reprodutíveis, especialmente quando se exclui a primeira avaliação. ${ }^{19}$ Afirma-se, ainda, que a primeira avaliação pode não refletir a real capacidade do indivíduo, sendo inadequado fazer deduções clínicas baseadas em um único teste isocinético. ${ }^{20}$

O uso de exercícios isocinéticos também tem sido estudado para a recuperação físico-funcional específica, demonstrando importantes efeitos em comparação a outros métodos de exercício. ${ }^{21}$ No entanto, em pacientes amputados ainda existe carência de publicações. Sabese que através dos exercícios isocinéticos é possível indicar a melhora da performance muscular no período pós-protético em atletas, principalmente quando estiver ligada ao retorno das atividades dos membros inferiores com a prótese, no restabelecimento da marcha. ${ }^{2} \mathrm{Em}$ atletas com deficiência, estudos isocinéticos podem ser usados como parâmetros indicativos para prescrição de treinamento específico. ${ }^{22}$

Os resultados obtidos em duas semanas de adaptação ao aparelho salientam a necessidade de o indivíduo avaliado estar adaptado ao isocinético e familiarizado com a execução dos movimentos concêntricos e excêntricos, especialmente de um membro que sofreu uma amputação, já que a ausência ou ineficiência dessa adaptação poderá comprometer os dados iniciais para a composição de protocolos de tratamento e/ ou treinamento. Sugere-se que os protocolos levem em consideração a adaptação ao equipamento por um tempo de aproximadamente duas semanas antes de iniciar as aquisições propriamente ditas. E, considerando que a amputação de membro inferior influencia o nível de atividade física praticada pelas pessoas amputadas, ${ }^{23}$ recomendam-se mais estudos de avaliações isocinéticas com sujeitos amputados.

\section{REFERÊNCIAS}

1. Gorgatti MG, Böhme MTS. Autenticidade científica de um teste de agilidade para indivíduos em cadeira de rodas. Rev Paul Educ Fís. $2003 ; 17(1): 41-50$.

2. Silva GC, Nery CAS, Chamlian TR, Buck GR. Avaliação isocinética em amputações Tanstibiais análise da força muscular dos flexores e extensores dos joelhos. Rev Inspirar Mov Saude. 2013;6(5)13-7.

3. Chatanooga Group INC. Kin-Com: Clinical desk reference. Rev A. 1995; PN 57682(6).

4. Afzali L, Fumi K, James Z, Phylls B, Robinson B. A new method for the determination of the characteristic shape of an isokinetic quadriceps femoris muscle torque curve. Phys Ther. 1992 Aug;72(8):585-92; discussion 593-5.

5. Pacheco GMR, Flores VO, Guadarrama, BJH, Chávez ADD, Díez GMP, García VG. Fortalecimiento muscular con ejercicios isocinéticos en pacientes amputados por arriba de rodilla en período preprotésico estudio de 10 casos. Rev Mex Med Fis Rehab. 2004;16(4):104-9.

6. Freitas CLR, Candotti CT, Vaz MA. Estudo comparativo de torques isocinéticos em atletas dos 11ํㅡogos da juventude. In: Anais do VIII Congresso Brasileiro de Biomecânica; 1999; Florianópolis/SC. p. 179-84.

7. Rebelo AN, Oliveira J. Relação entre a velocidade, a agilidade e a potência muscular de futebolistas profissionais. Rev Port Cien Desp. 2006;6(3):342-8

8. Silva GJ. Avaliação isocinética dos flexores e extensores de joelho [Monografia]. Florianópolis: UESC; 2001.

9. Signorelli MC, Cancelier M, Mazzucco A, Kurban E. A estimulação russa no fortalecimento do membro residual de amputados. Rev Bras Med Esporte. 2002;8(5):192-3.

10. Prentice WE, Voight ML. Técnicas em reabilitação musculoesquelética. Porto Alegre: Artmed; 2003.

11. Cahalan TD, Johnson ME, Liu S, Shao EY. Quantitative measurements of hip strength in different age groups. Clin Orthop Relat Res. 1989 Sept;(246):136-45.

12. Chatrenet Y, Kerkour K. Fisioterapia das lesões ligamentares do joelho no atleta. São Paulo: Manole; 2002.

13. Adkins DL, Boychuk J, Remple MS, Kleim JA. Motor training induces experience-specific patterns of plasticity across motor cortex and spinal cord. J Appl Physiol (1985). 2006 Dec;101(6):1776-82.

14. Enoka RM. Bases neuromecânicas da cinesiologia. 2ª ed. São Paulo: Manole; 2000.

15. Devir Z. Isokinetics: muscle testing, interpretation, and clinical applications. Edinburgh: Churchill Livingstone; 1995.

16. Higbie EJ, Cureton KJ, Warren III GL, Prior BM. Effects of concentric and eccentric training on muscle strength, cross-sectional area, and neural activation. J Appl Physiol (1985). 1996 Nov;81(5):2173-81.

17. Krotkiewski M, Aniansson A, Grimby G, Björntorp P, Sjöström L. The effect of unilateral isokinetic strength training on local adipose and muscle tissue morphology, thickness, and enzymes. Eur J Appl Physiol Occup Physiol. 1979;42(4):271-81.

18. Carvalho P, Cabri J. Avaliação isocinética da força dos músculos da coxa em futebolistas. Rev Port Fisioterapia Desp. 2007; $1(2): 4-13$ 
19. Filippin NT, Vieira WHB, Costa PHL. Repetibilidade de medidas isocinéticas dos músculos adutores e abdutores do quadril. Rev Bras Educ Fís Esporte. 2006;20(2):131-9.

20. Soares ASOC, Soares RJ, Serrão JC, Amadio AC. Análise da Componente vertical de Reação do Solo de amputados transtibiais. In: [Anais...] $11^{\circ}$ Congresso Brasileiro de Biomecânica; 2005; João Pessoa. João Pessoa: Sociedade Brasileira de Biomecânica; 2005 . p. 167-71.

21. Melo SIL, Oliveira J, Detânico RC, Palhano R, Schwinden RM, Andrade MC, Santos JOL. Avaliação da força muscular de flexores e extensores de joelho em indivíduos com e sem osteoartrose. Rev Bras Cineantropom Desempenho Hum. 2008;10(4):335-40.

22. Secchi LLB, Muratt MD, Saccol MF, Greve JMD. Avaliação isocinética em nadador amputado de membro superior: relato de caso. Acta Fisiatr. 2009;16(4):196-9.

23. Tonon Luz SC. Valoración del daño corporal en amputados de miembros inferiores [Tese]. [Sevilla, Espanã]: Universidad de Valladolid; 2010. 